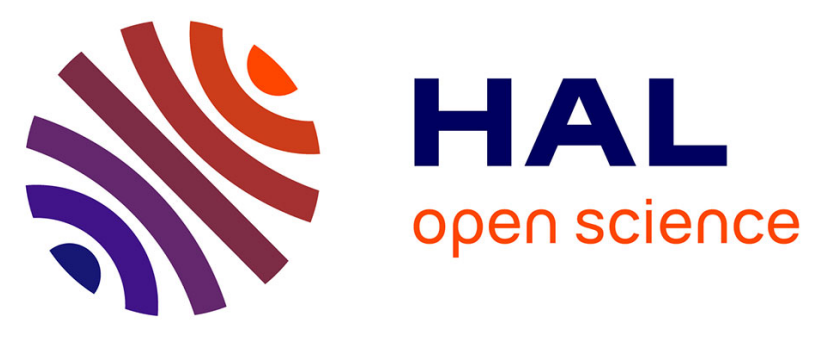

\title{
Dissociating effect of salivary gland extract from Ixodes ricinus on human fibroblasts: Potential impact on Borrelia transmission
}

Amandine Boeuf, Gilles Schnell, Quentin Bernard, Aurelie Kern, Benoit Westermann, Laurence Ehret-Sabatier, Antoine Grillon, Frédéric Schramm, Benoît Jaulhac, Nathalie Boulanger

\section{To cite this version:}

Amandine Boeuf, Gilles Schnell, Quentin Bernard, Aurelie Kern, Benoit Westermann, et al.. Dissociating effect of salivary gland extract from Ixodes ricinus on human fibroblasts: Potential impact on Borrelia transmission. Ticks and Tick-borne Diseases, 2019, 10 (2), pp.433-441. 10.1016/j.ttbdis.2018.12.005 . hal-02325974

\section{HAL Id: hal-02325974 \\ https://hal.science/hal-02325974}

Submitted on 21 Oct 2021

HAL is a multi-disciplinary open access archive for the deposit and dissemination of scientific research documents, whether they are published or not. The documents may come from teaching and research institutions in France or abroad, or from public or private research centers.
L'archive ouverte pluridisciplinaire HAL, est destinée au dépôt et à la diffusion de documents scientifiques de niveau recherche, publiés ou non, émanant des établissements d'enseignement et de recherche français ou étrangers, des laboratoires publics ou privés.

\section{(ㄷ)(1) $\$$}

Distributed under a Creative Commons Attribution - NonCommerciall 4.0 International 


\section{Dissociating effect of salivary gland extract from Ixodes ricinus on}

\section{2 human fibroblasts: potential impact on Borrelia transmission}

3 Amandine Boeuf $^{1,2}$, Gilles Schnell ${ }^{1,2}$, Quentin Bernard $^{3}$, Aurelie Kern ${ }^{3}$, Benoît

4 Westermann $^{1,2}$, Laurence Ehret-Sabatier ${ }^{1,2}$, Antoine Grillon ${ }^{3}$, Frederic Schramm ${ }^{3}$, Benoît

5 Jaulhac $^{3}$, Nathalie Boulanger ${ }^{3 *}$

$6{ }^{1}$ Laboratoire de Spectrométrie de Masse BioOrganique, Université de Strasbourg, IPHC,

7 France.

${ }^{2}$ CNRS, UMR7178, Strasbourg, France.

${ }^{3}$ EA7290, Virulence bactérienne précoce, groupe Borréliose de Lyme, Facultés de médecine et de pharmacie, Université de Strasbourg, France.

*Correspondence to:

\section{nboulanger@unistra.fr}

EA7290 : Virulence bactérienne précoce : groupe Borrelia

Institut de Bactériologie, 3 rue Koeberlé, 67000 Strasbourg, France

Tel: +33 3695514 49, Fax: +33369551698

$\underline{\text { Key words: }}$ Tick saliva, Fibroblast, Borrelia, Ixodes, histone H4, Mass spectrometry, feeding pool

Abbreviations: SGE, salivary gland extract; FB, fibroblast; PTM, post translational modification; AMP, antimicrobial peptides 


\section{ABSTRACT}

Understanding the mechanism of pathogen transmission is essential for the development of strategies to reduce arthropod-borne diseases. The pharmaco- and immunomodulatory properties of insect and acarine saliva play an essential role in the efficiency of pathogen transmission. The skin as the site where arthropod saliva and pathogens are inoculated represents the key interface in vector-borne diseases. We identified tick molecules potentially involved in pathogen transmission, using micro-HPLC and mass spectrometry, followed by in vitro assays on human skin cells. Histone $\mathrm{H} 4$ isolated from Ixodes ricinus salivary gland extract was identified as a molecule with a dissociating effect on human primary fibroblasts. This histone might be involved in the formation of the feeding pool formed around the tick mouthparts and responsible of tissue necrosis in the vertebrate host. Thanks to its selective antimicrobial activity, it may also sterilize the feeding pool and facilitate transmission of pathogens such as Borrelia burgdorferi sensu lato. 
Salivary gland extract and Borrelia transmission

\section{INTRODUCTION}

Hard ticks of the Ixodidae family are involved in numerous tick-borne diseases caused by diverse pathogens including bacteria, viruses or parasites. Certain Ixodes species are obligate hematophagous vectors for bacteria including Borrelia burgdorferi sensu lato, Rickettsia, Anaplasma, the parasite Babesia or the tick-borne encephalitis virus (de la Fuente et al., 2008). These pathogens are transmitted when a tick attaches to a host through its sophisticated mouthparts, the hypostome and the chelicerae. The skin injury eventually develops to a feeding pool (Sonenshine and Anderson, 2014). During a tick blood meal which typically lasts for several days, the hard tick concurrently inoculates saliva to secure its blood meal by forming a cement layer around the mouthparts and by the secretion of pharmacologically and immunologically active molecules (Kazimírová and Stibrániová 2013). The salivary glands modify their structure during the blood meal and degenerate after the blood meal in some tick species (Alarcon-Chaidez, 2014; Kahl et al., 1990) and the tick detaches from the host to either molt (nymphs) or to die after laying eggs (female adults). The tissue damage very often develops to a skin necrosis after the tick blood meal (Krause et al., 2009).

Saliva plays a crucial role during the feeding process: it allows the tick to neutralize host hemostasis (vasoconstriction, platelet aggregation, blood clotting), innate immunity (inflammatory response, complement activation) and acquired immunity. For that purpose, tick saliva contains a wide range of pharmacologically active molecules (Francischetti et al., 2009; Hovius et al., 2008; Ribeiro et al., 1985) with anti-clotting (Chmelar et al., 2012; Francischetti et al., 2004; Narasimhan et al., 2004; Prevot et al., 2006), vasodilatory (Bowman et al., 1996; Dickinson et al., 1976) and anti-inflammatory properties (Beaufays et al., 2008; Paesen et al., 1999; Ribeiro and Mather, 1998; Sangamnatdej et al., 2002). In addition, tick saliva is able to target vertebrate host immune responses such as the complement cascade (Couvreur et al., 2008; Daix et al., 2007; Schroeder et al., 2007; Valenzuela et al., 2000), 
antimicrobial peptides (Kern et al., 2011; Marchal et al., 2011), B-cells (Hannier et al., 2004) and the T-cells (Anguita et al., 2002; Garg et al., 2006; Leboulle et al., 2002). In the context of tick-borne diseases, this cocktail of active molecules renders the infection of a host more efficient.

The skin of the vertebrate host is the key interface where the vector bites and inoculates its saliva containing the pathogens (Bernard et al., 2015, 2014). The epidermis with its keratinocytes represents the first barrier encountered by ticks. They overcome this barrier using their biting pieces to penetrate deeply into the skin and reach the dermis, where the saliva interacts with resident cells like dermal dendritic cells, mast cells or fibroblasts. Some pathogens already multiply in the dermis before disseminating to the target organs. Investigating these initial steps is essential to understand the further development of most of the vector-borne diseases and to develop new strategies to control these diseases (de la Fuente et al., 2017).

We have selected the causative agent of Lyme disease, Borrelia burgdorferi sensu stricto (ss), which is transmitted by certain Ixodes species in Europe to study these transmission mechanisms. In a previous study, we have shown the antialarmin effect of tick saliva on human keratinocytes (Marchal et al., 2011). We observed also that crude salivary gland extract induced a dissociating effect on fibroblast monolayer adherent to tissue culture plate (Schramm et al., 2012). Identification of the tick molecules responsible of this specific effect could help to understand the formation of the feeding pool, which is essential for the tick blood meal process and thus for the transmission of pathogens. Therefore, we performed a fractionation of tick salivary gland extract by micro RP-HPLC and tested the different chromatographic fractions for a potential dissociating effect on human dermal fibroblasts. A tick-borne histone $\mathrm{H} 4$ was identified in the active fractions by enzymatic digestion and 
nanoLC-MS/MS. This protein was further characterized by mass spectrometry. The biological significance of this protein is discussed in the context of B. burgdorferi sl transmission.

\section{MATERIALS AND METHODS}

\section{Tick salivary gland extract preparation and HPLC fractionation}

This research has been reviewed and approved by the Institutional Animal Care, CREMEAS (Comite Régional d'Ethique en Matière d'Expérimentation Animale). Protocols for all animal experiments were prepared according to their guidelines. Adult I. ricinus females, either originating from our in-house tick colony or collected in the field, were either fed on rabbit or on mouse for three days before being dissected. Tick salivary gland extract (SGE) was prepared from blood-fed females on day 3 as described previously (Marchal et al., 2011). SGE was tested for the presence of endotoxin by the Limulus assay.

Tick SGEs were then fractionated on a micro-HPLC system U3000 (Thermo Fischer Scientific, San Jose, USA). The solvent system consisted of $0.05 \%$ TFA in water (solvent A) and $0.045 \%$ TFA in ACN (solvent B). Detection was performed at $214 \mathrm{~nm}$. The system was equipped with a Dionex Acclaim PepMap C18 enrichment column $(500 \mu \mathrm{m}$ x 15 mm, $5 \mu \mathrm{m})$ and an Agilent Zorbax 300SB-C18 analytical column $(300 \mu \mathrm{m}$ x $15 \mathrm{~cm}, 3.5 \mu \mathrm{m})$. SGE corresponding to the equivalent of 3 ticks was loaded during 3 min on the enrichment column at a flow rate of $15 \mu \mathrm{L} / \mathrm{min}$ with $0.1 \%$ TFA in water. Elution was performed at a flow rate of $4 \mu \mathrm{L} / \mathrm{min}$ with the following step gradient: a 5 min stage at $2 \%$ B followed by a $2-9.5 \%$ B linear gradient over $15 \mathrm{~min}$, then a $9.5-29.5 \%$ B linear gradient over $80 \mathrm{~min}$, then a $29.5-48 \%$ B linear gradient over $185 \mathrm{~min}$ and a final 5 min stage at $80 \% \mathrm{~B}$.

\section{Measurement of the effect of tick SGE on human fibroblasts (FBs)}

Primary human dermal fibroblasts (FBs) (NHDF, Promocell, Germany) were maintained in FGM2 medium. Cells were used at passage 3 to 5 and plated into 48 -well plates. At confluence and one day before the assays, FGM2 medium was replaced by FGM medium 
without fetal calf serum. SGE micro-HPLC fractions were transferred onto FBs and incubated for $24 \mathrm{~h}$. Controls were performed with equivalent $\mathrm{H}_{2} \mathrm{O} / 0.05 \%$ TFA (v/v) and ACN/0.045\% TFA (v/v) mixtures. The SGE effect was measured by observation of the cells under inverted microscope.

To evaluate more precisely the effect of SGE and histone, recombinant human histone H4 with his-tag (Sigma) (data not shown) or without his-tag (Biolabs) was incubated for 24h at different concentrations $(0,5,10$ and $20 \mu \mathrm{g} / \mathrm{mL})$ with FBs in 24-well plates. Positive control was performed with crude I. ricinus SGE at $20 \mu \mathrm{g} / \mathrm{ml}$. An irrelevant recombinant protein (Human HMGN1: High mobility group nucleosome-binding domain-containing protein 1, R\&D) was also tested on fibroblasts as negative control.

The viability of FBs was assessed by Trypan blue. Supernatants of control FBs, FBs treated with SGE or with histone $(20 \mu \mathrm{g} / \mathrm{ml})$ were collected and cells counted with Trypan blue. Then, the remaining adherent FBs were counted in a Neubauer cell after trypsination, and FBs viability was determined by Trypan blue staining.

\section{Mass spectrometry measurements}

Intact mass measurements of proteins present in fractions of interest were performed on a hybrid electrospray quadrupole time-of-flight mass spectrometer (Synapt G2 HDMS, Waters, Manchester, U.K.) coupled to an automated chip-based nanoelectrospray device (Triversa Nanomate, Advion Biosciences, Ithaca, U.S.) operating in the positive ion mode.

For nanoLC-MS/MS, proteins present in fractions of interest were digested by using a liquid trypsin digestion protocol as described in supplementary data. Digested peptides were analyzed on an Agilent 1100 series nanoHPLC-Chip system (Agilent Technologies, Palo Alto, USA) hyphenated to an amaZon ion trap (Bruker Daltonics, Bremen, Germany) as described (Schnell et al., 2014) with an $\mathrm{ACN}$ gradient in $0.1 \% \mathrm{HCO}_{2} \mathrm{H}$. Detailed chromatographic and MS conditions are provided in supplementary data. For the 
characterization of histone $\mathrm{H} 4$, proteins present in fractions of interest (or recombinant histone H4), were digested by using a liquid AspN digestion protocol as described in supplementary data. Digested peptides were analyzed on a nanoACQUITY UPLC system coupled to a QExactive Plus (Thermo Fisher Scientific, MA) equipped with a nanospray Flex ${ }^{\mathrm{TM}}$ ion source (supplementary data). The peptides were trapped on a nanoAcquity UPLC precolumn (Symmetry C18 Trap, $5 \mu \mathrm{m}, 180 \mu \mathrm{m} \times 20 \mathrm{~mm}$, Waters), then separated on a nanoAcquity UPLC column (BEH C18, $1.7 \mu \mathrm{m}, 75 \mu \mathrm{m} \times 150 \mathrm{~mm}$, Waters) with an ACN gradient in $0.1 \%$ $\mathrm{HCO}_{2} \mathrm{H}$. Detailed chromatographic and MS conditions are given in supplementary data.

\section{MS/MS data interpretation}

Collected mass data were converted into mgf files using DataAnalysis 4.0 (AmaZon-Bruker Daltonics) or MSConvert 3.0 (Q-Exactive Plus) softwares. The MS/MS data obtained from AmaZon were analyzed using two search engines: the MASCOT 2.3.2 (Matrix Science, London, UK) and OMSSA 2.1.9 algorithms as described (Schnell et al., 2014) against an inhouse generated target-decoy protein database composed of protein sequences of Ixodes downloaded from National Center for Biotechnology Information non redundant database (NCBInr) and of common contaminant proteins such as porcine trypsin and human keratins (2 x 21,571 entries on December 16, 2012). Spectra were searched with a mass tolerance of 0.5 Da for MS and MS/MS data. For the data obtained from AspN digestion and Q-Exactive Plus analyses, spectra were searched with a mass tolerance of $5 \mathrm{ppm}$ for MS and 0.07 Da for MS/MS data, allowing a maximum of one missed cleavage with AspN enzyme and with acetylation, mono-, di- and tri-methylation of both lysine and arginine and oxidation of methionine specified as variable modifications.

\section{Biological activity of histone $\mathrm{H} 4$ on pathogenic and commensal bacteria.}


B. burgdorferi sensu lato (sl) were used at low passage. B. burgdorferi ss 297 (isolated from cerebrospinal fluid in the United States- Dr. A. Steere) were grown at $33^{\circ} \mathrm{C}$ in BarbourStoenner-Kelly (BSK) medium supplemented with 6\% rabbit serum for 4 days. B. afzelii strain NE4049 was cultured in modified BSK-H complete medium (Sigma) at $33^{\circ} \mathrm{C}$ in anaerobic conditions. We used a starting concentration of $10^{5}$ Borrelia/well in $100 \mu 1$. Staphylococcus epidermidis ATCC12228, Micrococcus luteus and Escherichia coli ATCC 25922 were grown in Mueller-Hinton (MH) medium overnight. A secondary culture in fresh MH medium was incubated for 3 to 4 h. Then, S. epidermidis, M. luteus or E. coli cultures were centrifuged and incubated with different concentrations (from 0 to $100 \mu \mathrm{g} / \mathrm{mL}$ ) of gentamycin (Promocell) or human cathelicidin antimicrobial peptide (LL-37) as positive controls and recombinant human histone H4 without his-tag (Biolabs), or I. ricinus SGE at $37^{\circ} \mathrm{C}$ for $3 \mathrm{~h}$. After incubation, bacteria were plated on blood agar plates at $37^{\circ} \mathrm{C}$ for $24 \mathrm{~h}$. CFU were counted and percentage of survival was calculated according to the negative, i.e., untreated control.

B. burgdorferi sl was incubated in microtiter plates for $24 \mathrm{~h}$ in serum-free FGM medium with different concentrations of gentamicin and LL-37 (positive controls), or human histone H4 and tick SGE, and then transferred in 1.5 ml-tubes of BSK for an additional 5 days. Then the Borreliae were counted and percentage of motility was calculated according to the negative, i.e., untreated control.

\section{RESULTS}

\section{Identification of tick SGE fractions with dissociating activity}

Preliminary micro-HPLC analyses were performed to assess the biological reproducibility and the amount of injected SGE needed to perform reproducible chromatograms (data not shown). An equivalent of three ticks per injection was found to be sufficient to obtain a satisfactory 
HPLC profile. Elution conditions were optimized with shallow gradients in the zone of SGE effect. Five active fractions between 182 and 192 min were identified with a dissociating effect on FBs (fractions 2 to 6 in Figure 1A). The maximum dissociating effect was observed in the fractions eluted between 184 min and $192 \min$ (fractions 3 to 6 in Figure 1B). No effect was observed before $182 \mathrm{~min}$ and after $192 \min$ (fractions 1 and 7 in Figure 1B).

\section{Histone H4 identification}

To identify tick SGE proteins responsible for the dissociating effect on FBS, fractions of interest were analyzed by a nanoLC-MS/MS strategy after a tryptic digestion. As a large number of proteins was expected, fractions neighboring active samples were analyzed as well to exclude proteins which might also be present in non-active fractions. We identified a total of 11 different proteins in active fractions (Table 1). Histone $\mathrm{H} 4$ was present in four (fractions 3 to 6) out of the five active fractions. It was present as single peptide in the active fraction 5, and with only one other peptide in fractions 3,5 and 6 , but with as many as 11 peptides (with OMSSA) in fraction 4. The sequence of the protein is presented in Figure 2. The identified peptides correspond to $66 \%$ sequence coverage. The missing part can be explained by a high proportion of lysine and arginine, leading to short peptides not well detected during nanoLCMS/MS. Tick SGE histone H4 was found to be $100 \%$ identical to human histone H4. We were able to show by Western blot that the tick histone present in SGE is recognized by a polyclonal rabbit serum directed to human histone, as well as to human recombinant histone H4 (Supplementary data).

ESI-TOF mass spectrometry of histone H4 isolated from SGE revealed an average mass of 11,306 Da (Figure 3). On the other hand, the average mass calculated for the sequence without post-translational modifications (PTM) was $11,236 \mathrm{Da}$, resulting in a difference of 70 $\mathrm{Da}$, which corresponds to one acetylation and two methylations on the $\mathrm{N}$-terminal part. 
Salivary gland extract and Borrelia transmission

216 Further characterization of PTMs present on histone H4 by using AspN digestion and nanoLC-MS/MS confirmed the identification of histone $\mathrm{H} 4$ with $77 \%$ sequence coverage. However, identification of the N-terminal peptide carrying the PTMs was not successful.

\section{Effect of salivary gland extract and recombinant histone on human fibroblasts}

As I. ricinus histone $\mathrm{H} 4$ is $100 \%$ homologous to human histone, we used the commercially available human recombinant histone $\mathrm{H} 4$ to confirm the dissociating effect of histone $\mathrm{H} 4$ on FBs. The stimulation on FBs confirmed the ability of this surrogate histone protein to induce a cell effect within $24 \mathrm{~h}$. The activity was concentration-dependent with a significant effect at $20 \mu \mathrm{g} / \mathrm{mL}$ (Figure 4a to $4 \mathrm{~d}$ ). It was, however, less strong than the effect observed with crude SGE (Figure 4e). This could be due to the fact that native histone H4 in SGE has a more potent effect than the recombinant histone that lacks post-translational modifications (PTMs), especially on the N-terminal part. The effect is protein-specific since an irrelevant recombinant human protein, HMGN1 had no effect on the cell monolayer (Figure 4f). It is also cell-specific since human primary keratinocytes were not affected at confluence by crude tick SGE (data not shown). In addition, we observed a retention time of 187 min when analyzing the recombinant histone $\mathrm{H} 4$ protein by micro-HPLC, which is consistent with the active fractions in SGEs.

To ensure that the dissociating effect of SGE on FBs was not only present in Ixodes ticks maintained under laboratory conditions, we also tested SGE of adult ticks collected in the field. Indeed, the SGE from these ticks showed a similar effect on FBs (data not shown). Furthermore, two different hosts, rabbit and mouse, were tested to verify that the effect was not linked to a specific vertebrate host. We observed a dissociating effect of SGE in any host the tick used for the blood meal: tick SGE isolated after feeding on either rabbit or mouse produced a dissociating effect (data not shown). 
Salivary gland extract and Borrelia transmission

240

241

242

243

244

To assess more precisely the effect of SGE on human FBs, the cell viability was measured by Trypan Blue. No cells were seen in the supernatant of the untreated FBs (Figure 5). Recombinant Human histone had a significant effect on the shape of the cells but very few cells were found in the suspension. SGE induced a strong dissociating effect on FBs with around $50 \%$ of cells in suspension (Figure 5). Subsequently, the remaining adherent cells in each well were treated with trypsin. Trypan blue staining and counting of these cells demonstrated that more than $90 \%$ of the cells were viable. We can therefore conclude that SGE has rather a dissociating than a lytic effect on FBs. Interestingly, FBS co-incubated with SGE extract adhered again to the wells 72 hours later, confirming that they were alive (data not shown).

\section{Antimicrobial activity assays}

Histone H4 is known for its antimicrobial activity (Lee et al., 2009). To test whether the identified histone might affect Borrelia and the skin microflora, we co-incubated Borrelia or different bacteria, Gram-positive (M. luteus and S. epidermidis) and Gram-negative (E. coli), with histone H4 or SGE, or with gentamycin antibiotics or LL-37 (human antimicrobial peptide, cathelicidin), both as positive controls for killing effect. Histone H4 affected $S$. epidermidis, M. luteus and E. coli but not the pathogenic bacteria, B. burgdorferi ss and B. afzelii (Figure 6). S. epidermidis, a commensal of the skin (Figure 6A), was less affected by histone $\mathrm{H} 4$ than E. coli and M. luteus (Figure 6B and C). In contrast, we did not notice any effect of tick SGE extract on commensal or pathogenic bacteria. On the other hand LL-37, a well-known antimicrobial peptide of the human skin, showed an antibacterial effect in all bacteria tested including Borrelia, as it was already described earlier (Lusitani et al., 2002). The histone H4 present in SGE did not exhibit any antimicrobial activity, whereas the pure recombinant histone $\mathrm{H} 4$ did. 
Salivary gland extract and Borrelia transmission

265

266 
Salivary gland extract and Borrelia transmission

267

268

269

270

271

272

273

274

275

276

277

278

279

280

\section{DISCUSSION}

The pathogen transmission is a key event in the context of arthropod-borne diseases. In the initial mechanical process, the two chelicerae lacerate the host tissue, leading to cell injury and the formation of a feeding pool which damages the vascular endothelium and facilitates the blood meal uptake. Subsequently, the tick saliva comes into play to boost the process of the blood meal. This has been particularly well-studied in the context of anti-tick vaccines, since antibodies directed against tick proteins can block the blood meal and potentially the transmission of pathogens (Schuijt et al., 2011). At the skin interface, tick saliva exerts its pharmacological as well as its immunomodulatory properties (Kazimírová and Stibrániová 2013; Wikel 2013). The effect of tick saliva on different immune cells has also been well studied. However, its effect on the main resident cells of dermis, the skin FBs, has been poorly investigated. The precise mechanism of the feeding pool formation around the tick biting pieces is not elucidated. We have shown earlier the dissociating effect of I. ricinus tick salivary glands on primary human fibroblasts in culture plates (Schramm et al., 2012). Since this could explain the direct formation of the feeding pool during the tick blood meal, we wanted to identify and investigate the tick molecule(s) responsible for this effect on dermal fibroblasts. We identified histone $\mathrm{H} 4$ in tick salivary gland as the molecule inducing a partial dissociation of FBs, using micro-HPLC and mass spectrometry. The Trypan blue assay revealed that SGE in fact induces a dissociation of the FB monolayer after which most of the cells detach but remain alive in suspension after $24 \mathrm{~h}$ of incubation. Presumably, Histone H4 is not the only molecule responsible for this effect, since the surrogate purified recombinant molecule, a human histone $\mathrm{H} 4$ 100\% homologous to tick histone, did not produce the same strong effect as the tick SGE. Another explanation could be that the recombinant protein is not as effective as the native molecule since it misses the PTMs. 
Histones (H2A, H2B, H3, and H4) and DNA form in the nucleus the nucleosomes, folded in chromatin fibers. In the genome and transcriptome of Ixodes scapularis, five putative histones were identified and classified as IsH1, IsH2A, IsH2B, IsH3, and IsH4 (Cabezas-Cruz et al., 2016). All these histones except IsH4 were closely related to other tick histones from Ornithodoros coriaceus, Amblyomma variegatum, and Nuttalliella namaqua. The IsH4 was closely related to the mammalian histone $\mathrm{H} 4$, but not to $\mathrm{H} 4$ from other arthropods (CabezasCruz et al., 2016). Transcriptomic studies on salivary glands and midguts, performed during blood feeding of I. ricinus on the vertebrate host, revealed 34 transcripts coding for proteins associated with histone modifications (Kotsyfakis et al., 2015). PTMs (acetylation, phosphorylation, methylation or ubiquitination) are essential for gene transcription and part of the "histone code" (Gardner et al., 2011). The most common modifications observed for histone H4 are the mono-, di- or tri-methylation of lysine 20 (Jørgensen et al., 2013; Yang and Mizzen, 2009), the histidine phosphorylation (Besant and Attwood, 2012), and acetylation of lysine 16 (Shahbazian and Grunstein, 2007; Shia et al., 2006). We have not been able to identify the PTMs on the histone purified from SGE. However, the measured mass in tick salivary gland is the same as the one previously observed by Kawasaki (Kawasaki et al., 2008). These PTMs are important for the varied histone activities, including antimicrobial and lytic/dissociating activities. Histones are primarily located in the nucleus, but they can also be found in the cytoplasm or on the cell surface. They are abundantly synthesized, have a low turnover and constitute $30 \%$ of total protein synthesis (Thepparit et al., 2010). The Ixodes histone $\mathrm{H} 4$ is $100 \%$ homologous to the human histone $\mathrm{H} 4$. This is the reason why we used the recombinant human $\mathrm{H} 4$, commercially available, to run our different experiments.

Tick saliva activity on FBs in vitro has been previously described in female I. ricinus and in a second hard tick, female Amblyomma variegatum. The effect was associated with the presence of tick molecules targeting wound-healing growth factors such as the platelet- 
derived growth factor (PDGF). The related immunosuppressive effect on inflammation may facilitate the successful accomplishment of the tick blood meal. The tick saliva factors involved in these processes have not been identified so far (Hajnická et al., 2011). We hypothesize that it could be Histone H4 interacting with fibroblast growth factors and leading to an alteration of cytoskeletal actin filaments. Therefore, we further analyzed the morphological changes of human FBs. Trypan blue staining showed that most of the cells are viable in the supernatant but detached in high numbers. It has been shown that tick salivary glands degenerate during the blood meal, and then histone $\mathrm{H} 4$ might be released into saliva and the host skin (Alarcon-Chaidez, 2014). Interestingly, another histone, H2B, has also been detected in the active fractions. Histones, and in particular histone $\mathrm{H} 2 \mathrm{~B}$, are receptors for plasminogen. Their presence would also enhance all the inflammatory process (Das et al., 2007), promoting pathogens such as B. burgdorferi ss to diffuse into the target organs: joints, the heart and the nervous system. Extracellular histones seem to contribute to the hypocoagulability (Johansson et al., 2013) which could also facilitate the blood meal uptake. In addition, a histone H2B of $I$. scapularis has been shown in vitro to interact with Rickettsia felis, a bacterium transmitted by ticks, to facilitate tick cell ISE6 invasion (Thepparit et al., 2010). More recently, Anaplasma phagocytophilum, another bacterium transmitted by Ixodes spp., was shown to increase the levels of histone modifying enzymes to inhibit host cell apoptosis and facilitate pathogen infection (Cabezas-Cruz et al., 2016). Free histones have also been described to play a role in hemocytes and hemolymph of oysters involved in the process of ETosis (Extracellular Trap osis) (Bachère et al., 2015), and more generally in other invertebrates as an ancient immune defense mechanism (Robb et al., 2014). Free histones might participate in local immune response of the tick salivary glands.

Concerning the involvement of histone antimicrobial activity in innate immunity, it has been evidenced in different organisms (Kawasaki and Iwamuro, 2008; Robb et al., 2014). In 
invertebrates, truncated forms of histone H4 from the armyworm Spodoptera frugiperda Sf9 cells were reported to be antimicrobial, leading to lysis of Bacillus megaterium and Escherichia coli (Calles et al., 2005). Several studies demonstrated the histone effect in the defense of oyster (Dorrington et al., 2011; Poirier et al., 2014). In vertebrates, frog histones H2A known as buforins I and II showed potent antimicrobial activity (Park et al., 1996), whereas another work revealed the presence of histone H4 in the skin of the Japanese tree frog, Hyla japonica, with a lytic effect on red blood cells (Kawasaki et al., 2008). A potential anti-inflammatory function of the rat histone $\mathrm{H} 4$ variants was reported as well (Poirier et al., 2006). In that study, it was demonstrated that C-terminal peptides transcribed from rat histone H4 variants significantly inhibit the release of prostaglandin E2 and interleukine-8, two proinflammatory mediators. Finally in human, histone H4 from sebocytes has been identified to have antimicrobial activity (Lee et al., 2009).

We showed that the histone $\mathrm{H} 4$ produces diverse effects when tested on different bacteria. It has a lethal effect on commensal bacteria of the skin (S. epidermidis and M. luteus) and also on E. coli. On the other hand, it has no effect on the pathogenic Borrelia transmitted by the tick. This demonstrates the efficiency $B$. burgdorferi ss has developed in using its vector to assure pathogen transmission. In SGE, Histone H4 might be associated with other molecules that modulate its antimicrobial activity.

Some of the tick proteins target the pharmacology of the host (coagulation, pain, hemostasis...), whereas others target the immunity (complement cascade, innate and acquired immunity) (Kazimírová and Štibrániová, 2013; Wikel, 2013). We show here that tick histone $\mathrm{H} 4$ is likely to be essential in the formation of the feeding pool, thanks to its antimicrobial activity and its dissociating properties. It probably acts in synergy with other tick saliva proteins since its effect was less strong when used alone. This feeding pool could explain the 
365 inflammatory process at the bite site as well as the skin necrosis observed in certain patients, 366 and also described in animal models (Krause et al., 2009). H4 by its antimicrobial activity 367 could also create a sterile environment for the blood meal of the tick. The FBs, in their 368 interaction with Borrelia were described as a major player in Borrelia pathogenicity, by 369 secreting metalloproteases, inflammatory molecules (Lochhead et al., 2012; Marchal et al., 370 2009; Schramm et al., 2012; Wu et al., 2011; Zhao et al., 2007) and by internalizing Borrelia 371 (Wu et al., 2011). We postulate that FBs have a pivotal role during Lyme borreliosis infection, 372 first during the process of transmission as a target for tick saliva and by producing a sterile 373 niche for pathogens, and second as a potential cell involved in the persistence of Borrelia in 374 the skin once the direct effect of tick saliva has disappeared. 
Salivary gland extract and Borrelia transmission

376

377

378

379

380

381

382

383

384

385

386

387

388

389

390

391

392

393

394

\section{CONFLICT OF INTEREST}

The authors state no conflict of interest.

\section{ACKNOWLEDGEMENTS}

We thank Laurence Zilliox and Daniele Napolitano for technical assistance in Borrelia cultures and Philip Barth for English editing. This study was supported by the French Proteomics Infrastructure (ProFI; ANR-10-INSB-08-03). During the tenure of this study, A.B., G.S. and B.W. were supported by studentships from the French Ministry of Research. Q.B. and A.K. were supported by grants from the Conseil Régional d'Alsace and Direction Générale de l'Armement. 列 


\section{REFERENCES}

Alarcon-Chaidez, F.J., 2014. Salivary glands, in: Sonenshine, D., Roe, R.M. (Eds.), Biology of Ticks. Oxford University Press, pp. 163-205.

Anguita, J., Ramamoorthi, N., Hovius, J.W.R., Das, S., Thomas, V., Persinski, R., Conze, D., Askenase, P.W., Rincón, M., Kantor, F.S., Fikrig, E., 2002. Salp15, an Ixodes scapularis salivary protein, inhibits CD4+ T cell activation. Immunity 16, 849-859.

Bachère, E., Rosa, R., Schmitt, P., Poirier, A., Merou, N., Charrière, G., DestoumieuxGarzón, D., 2015. The new insights into the oyster antimicrobial defense: Cellular, molecular and genetic view. Fish Shellfish Immunol. 46, 50-64.

Beaufays, J., Adam, B., Menten-Dedoyart, C., Fievez, L., Grosjean, A., Decrem, Y., Prévôt, P.-P., Santini, S., Brasseur, R., Brossard, M., Vanhaeverbeek, M., Bureau, F., Heinen, E., Lins, L., Vanhamme, L., Godfroid, E., 2008. Ir-LBP, an Ixodes ricinus tick salivary LTB4-binding lipocalin, interferes with host neutrophil function. PLoS One 3, e3987. doi:10.1371/journal.pone.0003987

Bernard, Q., Jaulhac, B., Boulanger, N., 2015. Skin and arthropods: an effective interaction used by pathogens in vector-borne diseases. Eur. J. Dermatol. 25 Suppl 1, 18-22. doi:10.1684/ejd.2015.2550

Bernard, Q., Jaulhac, B., Boulanger, N., 2014. Smuggling across the Border: How ArthropodBorne Pathogens Evade and Exploit the Host Defense System of the Skin. J. Invest. Dermatol. 1-9. doi:10.1038/jid.2014.36

Besant, P.G., Attwood, P. V., 2012. Histone H4 histidine phosphorylation: kinases, phosphatases, liver regeneration and cancer. Biochem. Soc. Trans. 40, 290-293. doi:10.1042/BST20110605

Bowman, A.., Dillwith, J.., Sauer, J.., 1996. Tick salivary prostaglandins: Presence, origin and significance. Parasitol. Today 12, 388-396. doi:10.1016/0169-4758(96)10061-2

Cabezas-Cruz, A., Alberdi, P., Ayllón, N., Valdés, J., Pierce, R., Villar, M., De la Fuente, F., 2016. Anaplasma phagocytophilum increases the levels of histone modifying enzymes to inhibit cell apoptosis and facilitate pathogen infection in the tick vector Ixodes scapularis. Epigenetics. 11, 303-19.

Calles, K., Lindskog, E., Nossed, Å., Svensson, I., Häggström, L., 2005. Extracellular histone H4 from SF9 cells is antimicrobial, in: Gòdia, F., Fussenegger, M. (Eds.), Animal cell technology meets genomics, ESACT Proceedings. Springer Netherlands, pp. 155-157.

Chmelar, J., Calvo, E., Pedra, J.H.F., Francischetti, I.M.B., Kotsyfakis, M., 2012. Tick salivary secretion as a source of antihemostatics. J. Proteomics 75, 3842-54. doi:10.1016/j.jprot.2012.04.026

Couvreur, B., Beaufays, J., Charon, C., Lahaye, K., Gensale, F., Denis, V., Charloteaux, B., Decrem, Y., Prévôt, P.P., Brossard, M., Vanhamme, L., Godfroid, E., 2008. Variability and action mechanism of a family of anticomplement proteins in Ixodes ricinus. PLoS One 3, e1400. doi:10.1371/journal.pone.0001400

Daix, V., Schroeder, H., Praet, N., Georgin, J.-P., Chiappino, I., Gillet, L., De Fays, K., Decrem, Y., Leboulle, G., Godfroid, E., Bollen, A., Pastoret, P.-P., Gern, L., Sharp, P.M., Vanderplasschen, A., 2007. Ixodes ticks belonging to the Ixodes ricinus complex encode a family of anticomplement proteins. Insect Mol. Biol. 16, 155-166. doi:10.1111/j.1365-2583.2006.00710.x 
Das, R., Burke, T., Plow, E., 2007. Histone H2B as a functionally important plasminogen receptor on macrophages. Blood. 110, 3763-72.

de la Fuente, J, Antunes, S., Bonnet, S., Cabezas-Cruz, A., Domingos, A., Estrada-Peña, A., Johnson, N., Kocan, K., Mansfield, K., Nijhof, A., Papa, A., Rudenko, N., Villar, M., Alberdi, P., Torina, A., Ayllón, N., Vancova, M, Golovchenko, M, Grubhoffer, L, Caracappa, S., Fooks, A., Gortazar, C., Rego, R., 2017. Tick-pathogen interactions and vector competence: Identification of molecular drivers for tick-borne diseases. Front Cell Infect 7, 114.

de la Fuente, J., Estrada-Peña, A., Venzal, J., Kocan, K., Sonenshine, D., 2008. Overview: Ticks as vectors of pathogens that cause disease in humans and animals. Front. Biosci. 13, 6938-6946.

Dickinson, R.G., O’Hagan, J.E., Schotz, M., Binnington, K.C., Hegarty, M.P., 1976. Prostaglandin in the saliva of the cattle tick Boophilus microplus. Aust. J. Exp. Biol. Med. Sci. 54, 475-486.

Dorrington, T., Villamil, L., Gómez-chiarri, M., 2011. Upregulation in response to infection and antibacterial activity of oyster histone H4. Fish Shellfish Immunol. 30, 94-101.

Francischetti, I.M.B., Mather, T.N., Ribeiro, J.M.C., 2004. Penthalaris, a novel recombinant five-Kunitz tissue factor pathway inhibitor (TFPI) from the salivary gland of the tick vector of Lyme disease, Ixodes scapularis. Thromb. Haemost. 91, 886-898. doi:10.1267/THRO04050886

Francischetti, I.M.B., Sá-Nunes, A., Mans, B.J., Santos, I.M., Ribeiro, J.M.C., 2009. The role of saliva in tick feeding. Front. Biosci. 14, 2051-2088.

Gardner, K., Allis, C., Strahl, B., 2011. Operating on chromatin, a colorful language where context matters. J Mol Biol. 409, 36-46.

Garg, R., Juncadella, I.J., Ramamoorthi, N., Ashish, Ananthanarayanan, S.K., Thomas, V., Rincón, M., Krueger, J.K., Fikrig, E., Yengo, C.M., Anguita, J., 2006. Cutting edge: CD4 is the receptor for the tick saliva immunosuppressor, Salp15. J. Immunol. 177, 6579-6583.

Hajnická, V., Vančová-Štibrániová, I., Slovák, M., Kocáková, P., Nuttall, P., 2011. Ixodid tick salivary gland products target host wound healing growth factors. Int J Parasitol. 41, 213-23.

Hannier, S., Liversidge, J., Sternberg, J.M., Bowman, A.S., 2004. Characterization of the Bcell inhibitory protein factor in Ixodes ricinus tick saliva: a potential role in enhanced Borrelia burgdoferi transmission. Immunology 113, 401-8. doi:10.1111/j.13652567.2004.01975.x

Hovius, J.W.R., Levi, M., Fikrig, E., 2008. Salivating for knowledge: Potential pharmacological agents in tick saliva. PLoS Med. 5, 0202-0208.

Johansson, P., Windeløv, N., Rasmussen, L., Sørensen, A., Ostrowski, S., 2013. Blood levels of histone-complexed DNA fragments are associated with coagulopathy, inflammation and endothelial damage early after trauma. J Emerg Trauma Shock. 6, 171-5.

Jørgensen, S., Schotta, G., Sørensen, C.S., 2013. Histone H4 Lysine 20 methylation: key player in epigenetic regulation of genomic integrity. Nucleic Acids Res. gkt012. doi:10.1093/nar/gkt012

Kahl, O., Hoff, R., Knülle, W., 1990. Gross morphological changes in the salivary glands of Ixodes ricinus (Acari, Ixodidae) between bloodmeals in relation to active uptake of 
atmospheric water vapour. Exp Appl Acarol. 9, 239-58.

Kawasaki, H., Iwamuro, S., 2008. Potential roles of histones in host defense as antimicrobial agents. Infect. Disord. Drug Targets 8, 195-205.

Kawasaki, H., Iwamuro, S., Goto, Y., Nielsen, P., Conlon, J., 2008. Characterization of a hemolytic protein, identified as histone H4, from the skin of the Japanese tree frog Hyla japonica (Hylidae). Comp Biochem Physiol B Biochem Mol Biol. 149, 120-5.

Kazimírová, M., Stibrániová, I., 2013. Tick salivary compounds: their role in modulation of host defences and pathogen transmission. Front Cell Infect Microbiol 3, 1-17. doi:10.3389/fcimb.2013.00043

Kern, A., Collin, E., Barthel, C., Michel, C., Jaulhac, B., Boulanger, N., 2011. Tick saliva represses innate immunity and cutaneous inflammation in a murine model of lyme disease. Vector borne zoonotic Dis. Larchmont NY 11, 1343-50. doi:10.1089/vbz.2010.0197

Kotsyfakis, M., Schwarz, A., Erhart, J., Ribeiro, J., 2015. Tissue- and time-dependent transcription in Ixodes ricinus salivary glands and midguts when blood feeding on the vertebrate host. Sci Rep. 5, 9103.

Krause, P.J., Grant-Kels, J.M., Tahan, S.R., Dardick, K.R., Alarcon-Chaidez, F., Bouchard, K., Visini, C., Deriso, C., Foppa, I.M., Wikel, S., 2009. Dermatologic changes induced by repeated Ixodes scapularis bites and implications for prevention of tick-borne infection. Vector Borne Zoonotic Dis. 9, 603-10. doi:10.1089/vbz.2008.0091

Leboulle, G., Crippa, M., Decrem, Y., Mejri, N., Brossard, M., Bollen, A., Godfroid, E., 2002. Characterization of a novel salivary immunosuppressive protein from Ixodes ricinus ticks. J. Biol. Chem. 277, 10083-9. doi:10.1074/jbc.M111391200

Lee, D.-Y., Huang, C.-M., Nakatsuji, T., Thiboutot, D., Kang, S.-A., Monestier, M., Gallo, R.L., 2009. Histone H4 Is a Major Component of the antimicrobial action of human sebocytes. J. Invest. Dermatol. 129, 2489-2496. doi:10.1038/jid.2009.106

Lochhead, R.B., Sonderegger, F.L., Ma, Y., Brewster, J.E., Cornwall, D., Maylor-Hagen, H., Miller, J.C., Zachary, J.F., Weis, J.H., Weis, J.J., 2012. Endothelial cells and fibroblasts amplify the arthritogenic Type I IFN response in murine Lyme disease and are major sources of chemokines in Borrelia burgdorferi-infected joint tissue. J. Immunol. 189, 2488-2501. doi:10.4049/jimmunol.1201095

Lusitani, D., Malawista, S.E., Montgomery, R.R., 2002. Borrelia burgdorferi are susceptible to killing by a variety of human polymorphonuclear leukocyte components. J. Infect. Dis. 185, 797-804. doi:10.1086/339341

Marchal, C., Luft, B., Yang, X., Sibilia, J., Jaulhac, B., Boulanger, N., 2009. Defensin is suppressed by tick salivary gland extract during the in vitro interaction of resident skin cells with Borrelia burgdorferi. J. Invest. Dermatol. 129, 2515-7. doi:10.1038/jid.2009.73

Marchal, C., Schramm, F., Kern, A., Luft, B.J., Yang, X., Schuijt, T., Hovius, J., Jaulhac, B., Boulanger, N., 2011. Antialarmin effect of tick saliva during the transmission of lyme disease. Infect. Immun. 79. doi:10.1128/IAI.00482-10

Narasimhan, S., Montgomery, R.R., DePonte, K., Tschudi, C., Marcantonio, N., Anderson, J.F., Sauer, J.R., Cappello, M., Kantor, F.S., Fikrig, E., 2004. Disruption of Ixodes scapularis anticoagulation by using RNA interference. Proc. Natl. Acad. Sci. U. S. A. 101, 1141-1146. doi:10.1073/pnas.0307669100 
Paesen, G.C., Adams, P.L., Harlos, K., Nuttall, P.A., Stuart, D.I., 1999. Tick histaminebinding proteins: isolation, cloning, and three-dimensional structure. Mol. Cell 3, 661671. doi:10.1016/S1097-2765(00)80359-7

Park, C.B., Kim, M.S., Kim, S.C., 1996. A novel antimicrobial peptide from Bufo bufo gargarizans. Biochem. Biophys. Res. Commun. 218, 408-413. doi:10.1006/bbrc.1996.0071

Poirier, A., Schmitt, P., Rosa, R., Vanhove, A., Kieffer-Jaquinod, S., Rubio, T., Charrière, G., Destoumieux-Garzón, D., 2014. Antimicrobial histones and DNA traps in invertebrate immunity: evidences in Crassostrea gigas. J Biol Chem. 2014 Sep 5;289(36) 289, 24821-31.

Poirier, R., Lemaire, I., Lemaire, S., 2006. Characterization, localization and possible antiinflammatory function of rat histone H4 mRNA variants. FEBS J. 273, 4360-4373. doi:10.1111/j.1742-4658.2006.05444.X

Prevot, P.-P., Adam, B., Boudjeltia, K.Z., Brossard, M., Lins, L., Cauchie, P., Brasseur, R., Vanhaeverbeek, M., Vanhamme, L., Godfroid, E., 2006. Anti-hemostatic effects of a serpin from the saliva of the tick Ixodes ricinus. J. Biol. Chem. 281, 26361-26369. doi:10.1074/jbc.M604197200

Ribeiro, JM, Makoul, G., Levine, J., Robinson, D., Spielman, A., 1985. Antihemostatic, antiinflammatory, and immunosuppressive properties of the saliva of a tick, Ixodes dammini. J Exp Med. 161, 332-344.

Ribeiro, J.M.C., Mather, T.N., 1998. Ixodes scapularis:salivary kininase activity is a metallo dipeptidyl carboxypeptidase. Exp. Parasitol. 89, 213-221. doi:10.1006/expr.1998.4296

Robb, C., Dyrynda, E., Gray, R., Rossi, A., Smith, V., 2014. Invertebrate extracellular phagocyte traps show that chromatin is an ancient defence weapon. Nat Commun. 5, 4627.

Sangamnatdej, S., Paesen, G.C., Slovak, M., Nuttall, P.A., 2002. A high affinity serotoninand histamine-binding lipocalin from tick saliva. Insect Mol. Biol. 11, 79-86.

Schnell, G., Boeuf, A., Jaulhac, B., Boulanger, N., Collin, E., Barthel, C., De Martino, S., Ehret-Sabatier, L., 2014. Proteomic analysis of three Borrelia burgdorferi sensu lato native species and disseminating clones: Relevance for Lyme vaccine design. Proteomics 10.1002/pmic.201400177. doi:10.1002/pmic.201400177

Schramm, F., Kern, A., Barthel, C., Nadaud, S., Meyer, N., Jaulhac, B., Boulanger, N., 2012. Microarray analyses of inflammation response of human dermal fibroblasts to different strains of Borrelia burgdorferi sensu stricto. PLoS One 7, e40046. doi:10.1371/journal.pone.0040046

Schroeder, H., Daix, V., Gillet, L., Renauld, J.-C., Vanderplasschen, A., 2007. The paralogous salivary anti-complement proteins IRAC I and IRAC II encoded by Ixodes ricinus ticks have broad and complementary inhibitory activities against the complement of different host species. Microbes Infect. 9, 247-250. doi:10.1016/j.micinf.2006.10.020

Schuijt, T.J., Hovius, J.W., van der Poll, T., van Dam, a P., Fikrig, E., 2011. Lyme borreliosis vaccination: the facts, the challenge, the future. Trends Parasitol. 27, 40-7. doi:10.1016/j.pt.2010.06.006

Shahbazian, M.D., Grunstein, M., 2007. Functions of site-specific histone acetylation and deacetylation. Annu. Rev. Biochem. 76, 75-100. doi:10.1146/annurev.biochem.76.052705.162114 
Shia, W.-J., Pattenden, S.G., Workman, J.L., 2006. Histone H4 lysine 16 acetylation breaks the genome's silence. Genome Biol. 7, 217. doi:10.1186/gb-2006-7-5-217

Sonenshine, D., 1991. Biology of ticks 472 pages.

Sonenshine, D., Anderson, J., 2014. Mouthparts and digestive system, in: Sonenshine, D., ROE, R. (Eds.), Biology of Ticks. Oxford University Press, pp. 122-162.

Thepparit, C., Bourchookarn, A, Petchampai, N., Barker, S., Macaluso, K., 2010. Interaction of Rickettsia felis with histone H2B facilitates the infection of a tick cell line. Microbiology. 156, 2855-63.

Valenzuela, J.G., Charlab, R., Mather, T.N., Ribeiro, J.M.C., 2000. Purification, cloning, and expression of a novel salivary anticomplement protein from the tick, Ixodes scapularis. J. Biol. Chem. 275, 18717-18723. doi:10.1074/jbc.M001486200

Wikel, S.K., 2013. Ticks and tick-borne pathogens at the cutaneous interface: host defenses, tick countermeasures, and a suitable environment for pathogen establishment. Front. Microbiol. 4, 337. doi:10.3389/fmicb.2013.00337

Wu, J., Weening, E.H., Faske, J.B., Höök, M., Skare, J.T., 2011. Invasion of eukaryotic cells by Borrelia burgdorferi requires $\beta 1$ Integrins and Src kinase activity. Infect. Immun. 79, 1338-1348. doi:10.1128/IAI.01188-10

Yang, H., Mizzen, C.A., 2009. The multiple facets of histone H4-lysine 20 methylation. Biochem. Cell Biol. 87, 151-161. doi:10.1139/008-131

Zhao, Z., Fleming, R., McCloud, B., Klempner, M.S., 2007. CD14 mediates cross talk between mononuclear cells and fibroblasts for upregulation of matrix metalloproteinase 9 by Borrelia burgdorferi. Infect. Immun. 75, 3062-3069. doi:10.1128/IAI.00202-07 
TABLE

Table 1: Proteins identified in each active fraction of Ixodes ricinus SGE

\begin{tabular}{|c|c|c|c|c|}
\hline Fraction $^{1}$ & $\begin{array}{c}\text { Retention } \\
\text { time (min) }\end{array}$ & Identified proteins $^{2}$ & $\begin{array}{c}\text { Accession } \\
\text { number }\end{array}$ & $\begin{array}{c}\text { Dissociating } \\
\text { activity } \\
\end{array}$ \\
\hline 1 & $180-182$ & $\begin{array}{c}\text { cyclophilin A } \\
\text { heat shock protein, putative } \\
\text { histone } \mathrm{H} 2 \mathrm{~B} \text {, putative } \\
\text { calreticulin }\end{array}$ & $\begin{array}{l}\text { gi|} 67084095 \\
\text { gi|240972667 } \\
\text { gi|241568982 } \\
\text { gi|} 39725993 \\
\end{array}$ & No \\
\hline 2 & $182-184$ & $\begin{array}{c}\text { small heat shock protein, putative } \\
\text { histone } \mathrm{H} 2 \mathrm{~B} \text {, putative }\end{array}$ & $\begin{array}{l}\text { gi|} 241860225 \\
\text { gi| } 241568982\end{array}$ & Yes \\
\hline 3 & $184-186$ & $\begin{array}{c}\text { histone } \mathrm{H} 4 \text {, putative } \\
\text { histone } \mathrm{H} 2 \mathrm{~B} \text {, putative } \\
\text { ornithine decarboxylase, putative }\end{array}$ & $\begin{array}{l}\text { gi|} 241568987 \\
\text { gi|} 241568982 \\
\text { gi|} 24200134 \\
\end{array}$ & Yes \\
\hline 4 & $186-188$ & $\begin{array}{l}\text { histone } \mathrm{H} 4 \text {, putative } \\
\text { histone } \mathrm{H} 2 \mathrm{~B} \text {, putative } \\
\text { hypothetical protein } \\
\text { IscW_ISCW008323 }\end{array}$ & $\begin{array}{l}\text { gi|241568987 } \\
\text { gi|241568982 } \\
\text { gi|241652216 }\end{array}$ & Yes \\
\hline 5 & $188-190$ & histone $\mathrm{H} 4$, putative & gi|241568987 & Yes \\
\hline 6 & $190-192$ & $\begin{array}{c}\text { cyclophilin A } \\
\text { histone H4, putative } \\
\text { histone } 2 \mathrm{~A} \\
\text { fructose } 1,6 \text {-bisphosphate } \\
\text { aldolase, putative } \\
\text { ixoderin B4 } \\
\text { hypothetical protein } \\
\text { IscW_ISCW008323 }\end{array}$ & $\begin{array}{l}\text { gi|} 67084095 \\
\text { gi|} 241568987 \\
\text { gi|} 241251590 \\
\text { gi|} 241690479 \\
\text { gi|} 126360866 \\
\text { gi|} 241652216 \\
\end{array}$ & Yes \\
\hline 7 & $192-194$ & histone $\mathrm{H} 4$, putative & gi|241568987 & $\mathrm{No}$ \\
\hline
\end{tabular}

$599{ }^{1}$ Fractions are described by their number indicated in Figure 1.

$600{ }^{2}$ NanoLC-MS/MS data obtained after reduction of disulfide bridge, alkylation of cysteines and 601 enzymatic digestion by trypsin were analyzed using MASCOT and OMSSA search engines against an 602 in-house generated target-decoy protein database composed of protein sequences of Ixodes. 
Salivary gland extract and Borrelia transmission

604

605

606

607

608

609

610

611

612

613

614

615

616

617

618

619

620

621

622

623

624

625

\section{FIGURE LEGENDS}

\section{Figure 1: SGE fractionation and detection of dissociating effect on human FBs}

(A) UV chromatogram of SGE of Ixodes ricinus females, fed on rabbit for three days. Fractions were collected every two min. Fractions whose dissociating effect on human fibroblasts was measured are indicated (fractions 1 to 7). Fractions exhibiting an effect on human fibroblasts are indicated by a star $\left(^{*}\right)$.

(B) In vitro cultures of human FBs co-incubated with I. ricinus SGE obtained after microHPLC separation. Dissociating effect tested for fractions (1), (2), (3), (4), (5), (6) and (7). Activity was observed for (2) to (6). Scale bar corresponds to $100 \mu \mathrm{m}$.

\section{Figure 2: Histone H4 identification}

The sequence of histone H4 protein and the MS/MS spectra of the peptide ISGLIYEETR are presented. The protein was identified with a maximum of 11 peptides (highlighted in bold) representing a sequence coverage of $66 \%$.

\section{Figure 3: Intact mass measurement of histone $\mathrm{H} 4$ isolated from SGE}

The MS spectrum showing the different charge states was obtained by infusion on a Triversa NanoMate/Synapt G2 instrument. A protein with an average mass of $11305.92 \pm 0.11$ Da was mostly observed. 
Salivary gland extract and Borrelia transmission

626

627

628

629

630

631

632

633

634

635

636

637

638

639

640

641

642

643

644

645

646

647

648

649

650

Figure 4: Dissociating effect of Human recombinant histone $\mathrm{H} 4$ and crude SGE on human FBs

Images of human FBs co-incubated for 24 hours with 0 (a), 5 (b), 10 (c) or $20 \mu \mathrm{g} / \mathrm{mL}$ (d) of recombinant histone $\mathrm{H} 4$, with crude $\mathrm{SGE}$ at $20 \mu \mathrm{g} / \mathrm{mL}$ of proteins (e) or with an irrelevant recombinant protein (f). Scale bar corresponds to $100 \mu \mathrm{m}$.

Figure 5: Measure of cell viability and dissociating effect of salivary gland extract by Trypan blue.

The effect of salivary gland extract (SGE) and human recombinant Histone H4 on human primary fibroblasts was measured by Trypan blue. Commercial purified histones (Sigma and/or Biolab) were used to compare their potential dissociating effect on SGE. Non adherent fibroblasts were first counted in the supernatant. Then, after trypsin treatment, adherent cells were counted (data not shown).

Figure 6: Histone H4 but not whole SGE shows antimicrobial activity against pathogenic and commensal bacteria. (A) Staphylococcus epidermidis (S. epidermidis), (B) Micrococcus luteus (M. luteus) and (C) Escherichia coli ATCC 25922 (E. coli) were incubated for 3 hours in PBS with different concentrations of LL-37 or gentamicin (positive controls), tick salivary gland extract (SGE) or human recombinant histone H4. Then bacteria were plated on agar for 24 hours. CFU were counted and percentage of survival was calculated according to the negative control. (D) Borrelia burgdorferi ss (297) and (E) B. afzelii (NE4049) were incubated for 24 hours in KGM medium with different concentrations of gentamicin (positive control), LL-37, SGE or histone H4. Then the Borreliae were counted and percentage of survival was calculated according to the negative control. Results $( \pm$ SEM) are representative of at least three independent experiments with similar results. 
Salivary gland extract and Borrelia transmission

652

653

654

655

656

657

658

659

660

661

662

663

664

665

666

667

668

669

670

671

672

673

674

675

676

677

\section{SUPPLEMENTARY MATERIAL}

\section{Material and Method supplementary material}

\section{Exact mass measurement}

External calibration was performed with the multiply charged ions produced by $2 \mu \mathrm{M}$ horse heart myoglobin diluted in water/ACN/ $\mathrm{HCO}_{2} \mathrm{H}(50 / 50 / 1)$ and classical interface tuning parameters of the mass spectrometer $(\mathrm{Vc}=40 \mathrm{~V}, \mathrm{Pi}=2.1 \mathrm{mbar})$.

\section{Trypsin digestion and nanoLC-MS/MS analyses}

Proteins were digested by using a liquid trypsin digestion protocol. After evaporation, the fraction was re-suspended in a Tris- $\mathrm{HCl} 25 \mathrm{mM}$ pH 8.8 buffer. Proteins were reduced $1 \mathrm{~h}$ at $60^{\circ} \mathrm{C}$ by adding dithiothreitol to a final concentration of $10 \mathrm{mM}$. Then alkylation was performed by adding iodoacetamide to a final concentration of $30 \mathrm{mM}$ at room temperature in dark. Digestion was finally performed overnight by adding trypsin (Promega, Madison, WI) to a final concentration of $1.5 \mathrm{ng} / \mu \mathrm{L}$. After digestion, fractions were evaporated and resuspended in a $0.1 \%(\mathrm{v} / \mathrm{v})$ TFA aqueous solution.

Digested peptides were analyzed as described (Schnell et al., 2014) with the following adapted conditions. The solvent system consisted of $2 \% \mathrm{ACN}$ and $0.1 \% \mathrm{HCO}_{2} \mathrm{H}$ in water (solvent $\mathrm{A}$ ) and $2 \%$ water and $0.1 \% \mathrm{HCO}_{2} \mathrm{H}$ in $\mathrm{ACN}$ (solvent $\mathrm{B}$ ). A Zorbax 300SB-C18 analytical column (43 $\mathrm{mm} \times 75 \mu \mathrm{m}, 5 \mu \mathrm{m})$ was used and proteins were eluted with a 10-30\% B linear gradient over $1.5 \mathrm{~min}$, followed by a $30-70 \%$ B linear gradient over $7.5 \mathrm{~min}$ and a final 4 min stage at $85 \%$ B. For MS, the voltage applied to the capillary was set to $-1850 \mathrm{~V}$. In MS scanning, the Ion Charge Control was fixed at 100,000. For tandem MS experiments, the six most abundant doubly or triply charged ions were selected to be further isolated and fragmented by CID. Ions were excluded after 1 spectrum and released after $0.12 \mathrm{~min}$. In MS/MS scanning the Ion Charge Control was fixed at 300,000 and a total of 2 scans were averaged to obtain a MS/MS spectrum. 
Salivary gland extract and Borrelia transmission

678

679

680

681

682

683

684

685

686

687

688

689

690

691

692

693

694

695

696

697

698

699

700

\section{Characterization of histone $\mathrm{H} 4$}

Proteins present were digested by using a liquid AspN digestion protocol. After evaporation, the fraction was re-suspended in $25 \mathrm{mM} \mathrm{NH}_{4} \mathrm{HCO}_{3}$ containing $0.1 \%$ RapiGest $^{\mathrm{TM}}$, reduced 30 min at $60^{\circ} \mathrm{C}$ by adding dithiothreitol to a final concentration of $12 \mathrm{mM}$ and alkylated $30 \mathrm{~min}$ at room temperature by adding iodoacetamide to a final concentration of $40 \mathrm{mM}$ in the dark. An overnight digestion was performed by adding AspN (Promega, Madison, WI) in a 1/75 enzyme/protein ratio at $37^{\circ} \mathrm{C}$. After digestion, trifluoroacetic acid was added to a final concentration of $0.5 \%(\mathrm{v} / \mathrm{v})$ and the sample was incubated $45 \mathrm{~min}$ at $37^{\circ} \mathrm{C}$ to hydrolyze RapiGest $^{\mathrm{TM}}$. After centrifugation $(14,000 \mathrm{x} \mathrm{g}, 10 \mathrm{~min})$, the sample was desalted on Sep-Pak C18 cartridges (Waters, Milford, MA) prior to mass spectrometry analyses.

For nanoLC-MS/MS, the solvent system consisted of $0.1 \% \mathrm{HCO}_{2} \mathrm{H}$ in water (solvent A) and $0.1 \% \mathrm{HCO}_{2} \mathrm{H}$ in $\mathrm{ACN}$ (solvent $\mathrm{B}$ ). Trapping was performed for $3 \mathrm{~min}$ at a flow rate of 5 $\mu \mathrm{L} / \mathrm{min}$, with $99 \%$ of solvent $\mathrm{A}$ and $1 \%$ of solvent B. Elution was performed at a flow rate of $450 \mathrm{~nL} / \mathrm{min}$, using a linear gradient of $1-35 \% \mathrm{~B}$ over $35 \mathrm{~min}$ at $45^{\circ} \mathrm{C}$, followed by $50 \% \mathrm{~B}$ over 1 min and then $90 \%$ B over 5 min. Peptides eluting from the column were analyzed by a top 10 data-dependent MS/MS on a Q-Exactive Plus mass spectrometer (Thermo Fisher Scientific, MA). Resolution was set to 70,000 for MS scans and 17,500 for the data-dependent MS/MS scans. The MS AGC target was set to $3 \times 10^{6}$ counts, while MS/MS AGC target was set to $1 \times 10^{5}$. The MS scan range was from 300 to $1,200 \mathrm{~m} / \mathrm{z}$. MS and MS/MS scans were recorded in profile mode. HCD fragmentation was performed by applying normalized collision energy of 29. Dynamic exclusion was set to $1 \mathrm{~min}$. 


\section{Identification of Histone $\mathrm{H} 4$ in Ixodes ricinus SGE and saliva by Immunoblot}

702

703

704

705

\section{Material and methods:}

An SDS-PAGE of $12 \%$ was run with different antigens: recombinant human histone $\mathrm{H} 4$ (Biolabs: 11,23 kD; $95 \%$ purity), recombinant human histone H4-Histag (Sigma; 12kD; 75\% purity), two batches of Ixodes ricinus salivary gland extracts from laboratory reared tick colony (lab) or ticks collected in the field (wild) dissected at day 3 of the blood meal, Ixodes ricinus saliva collected at day 7 of the blood meal. The gel was then transferred onto a nitrocellulose membrane $(0,2 \mu \mathrm{m})$; after blocking of unspecific sites, the membrane was incubated either with a polyclonal rabbit serum against human histone 4 (Sigma) or preimmune rabbit serum diluted 1/200; the conjugate (goat anti-rabbit/HRPO: 1 /3000) was then incubated and the reaction revealed by chloronaphtol.

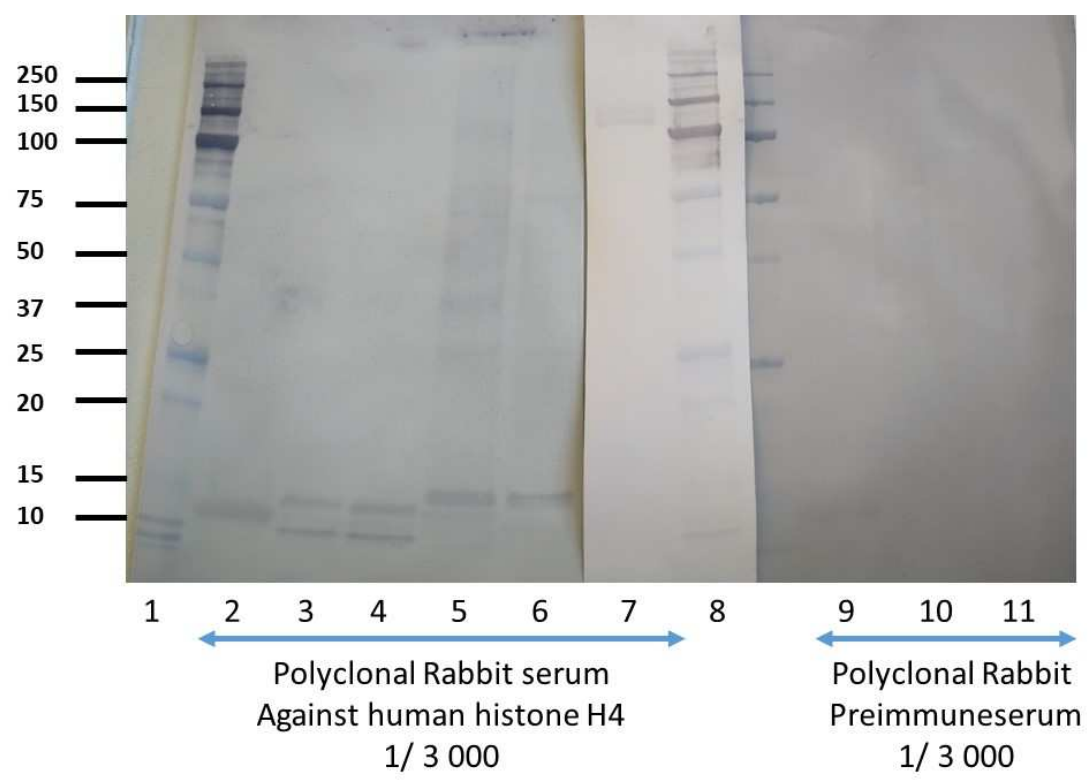

1, 8: MWM Biorad

2, 9: Human Histone $\mathrm{H} 4$ biolabs: $10 \mu \mathrm{g}$

3: Human histone-HisTag, Sigma, $5 \mu \mathrm{g}$

4: Human histone-HisTag, Sigma, $10 \mu \mathrm{g}$

5,10: Tick SGE (wild): $32 \mu \mathrm{g}$

6: Tick SGE (lab): $37 \mu \mathrm{g}$

7: Ixodes saliva (lab): $10 \mu \mathrm{g}$

11: Ixodes saliva: $10 \mu \mathrm{g}$

\section{Results:}

Histone $\mathrm{H} 4$ is detected in all the samples whatever the origin, human or tick. In ticks, the native histone has a higher molecular weight likely due to the presence of posttranslational modifications (PTM). In Ixodes saliva, we detected a very high molecular weight for histone.

This histone protein might be associated to another protein giving a high molecular weight 
Salivary gland extract and Borrelia transmission

718 protein complex (line 7). This complex is not detected with the preimmune rabbit serum (line 719 11)

720 
A

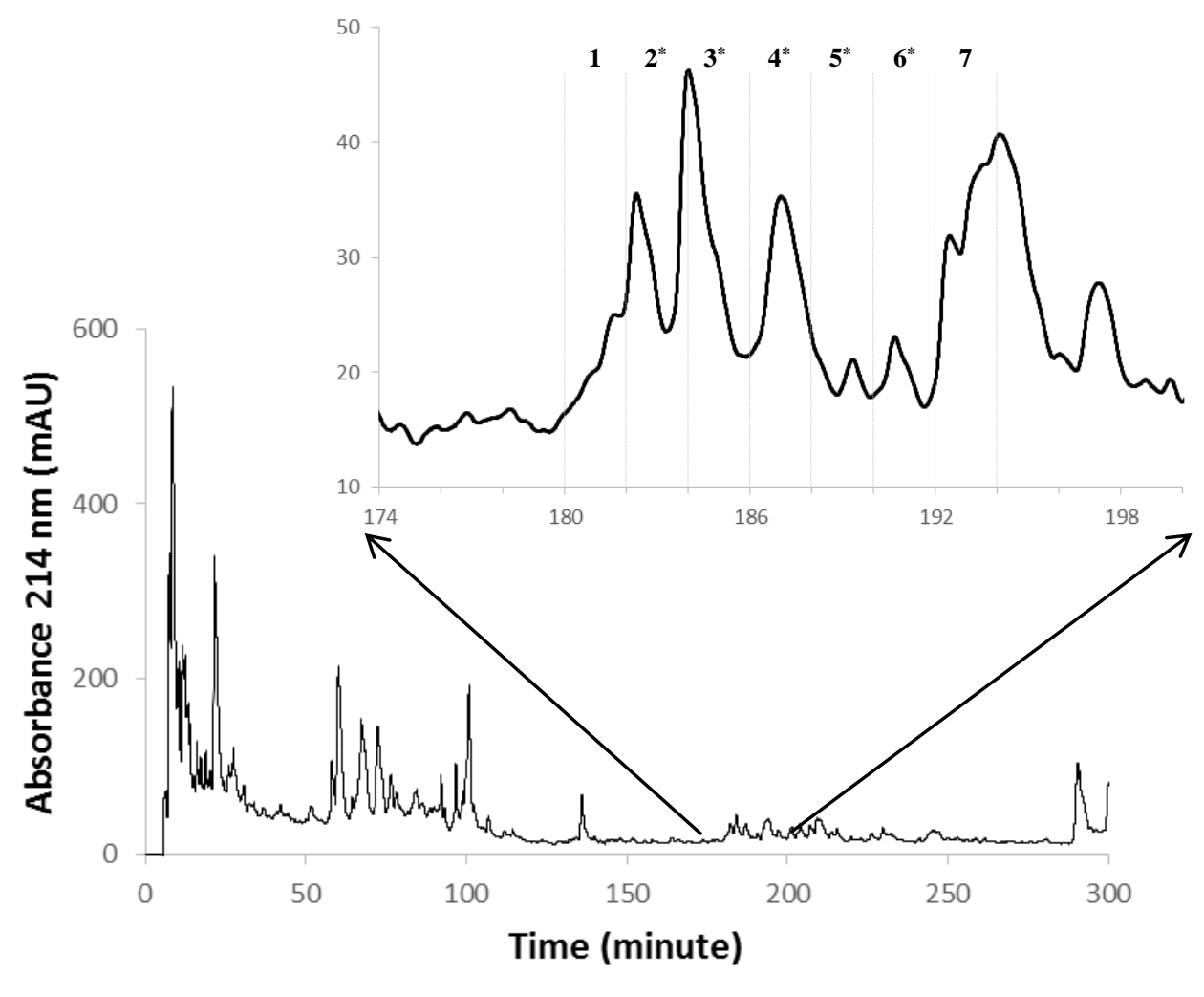

B
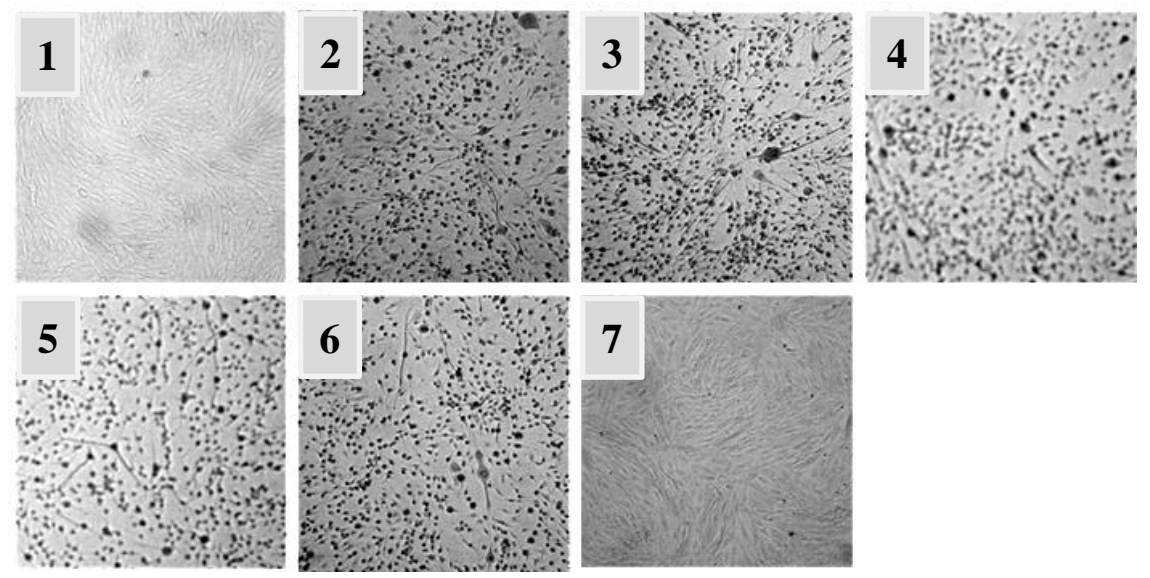

Figure 1 
MSGRGKGGKGLGKGGAKRHRKVLRDNIQGITKPAIRRLARRGGV KRISGLIYEETRGVLKVFLENVIRDAVTYTEHAKRKTVTAMDVV YALKRQGRTLYGFGG

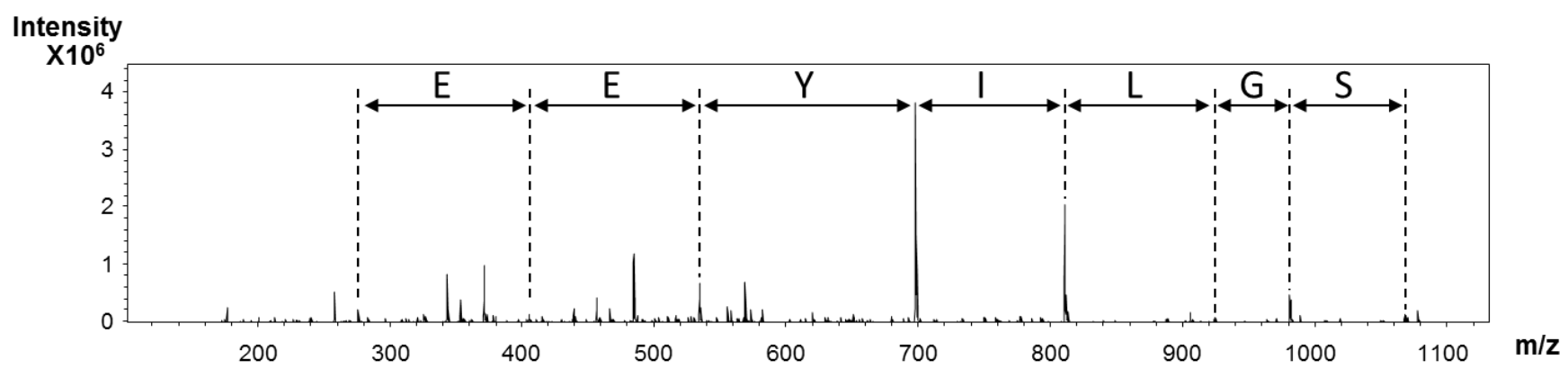

Figure 2 


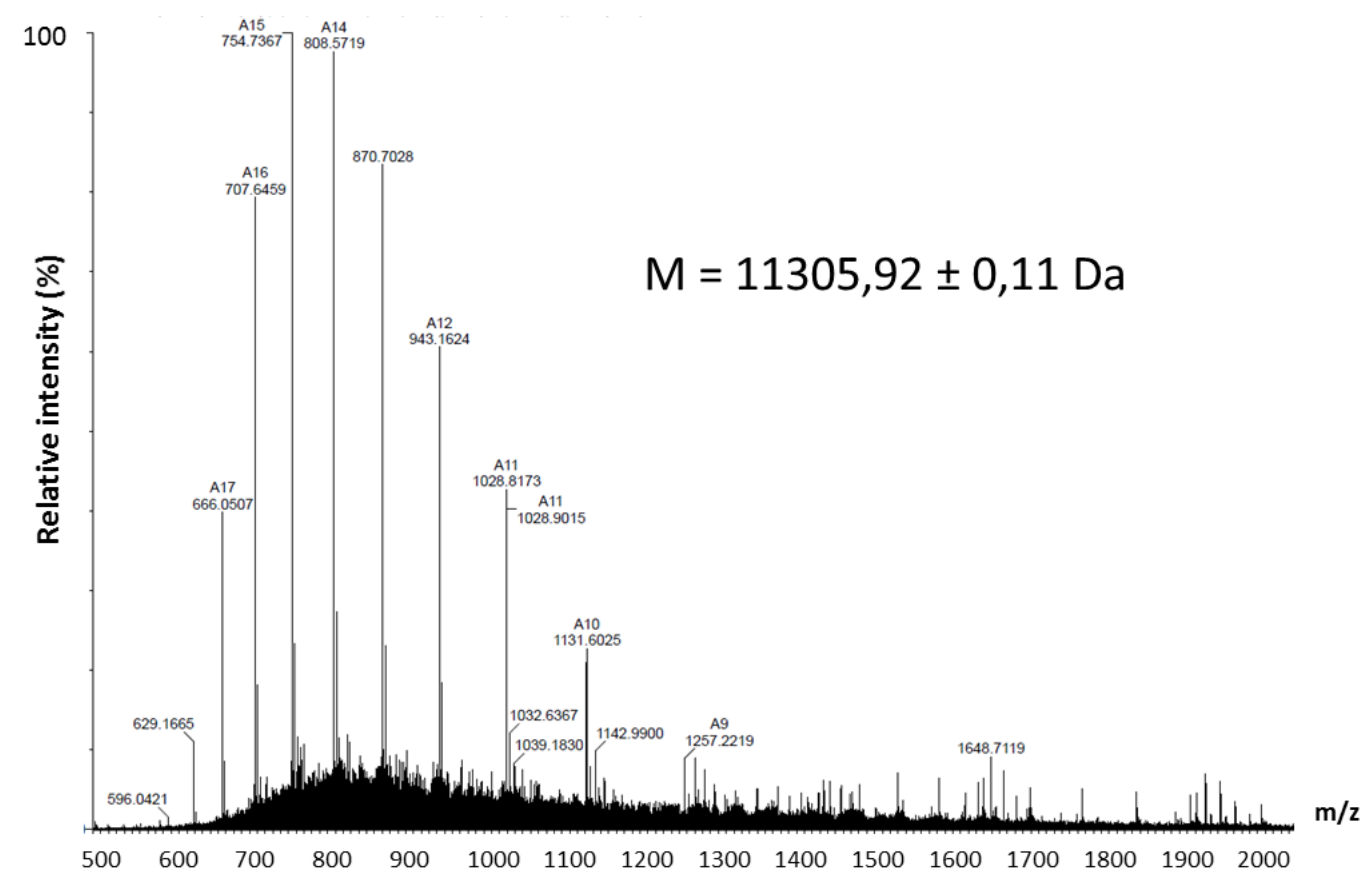

Figure 3 

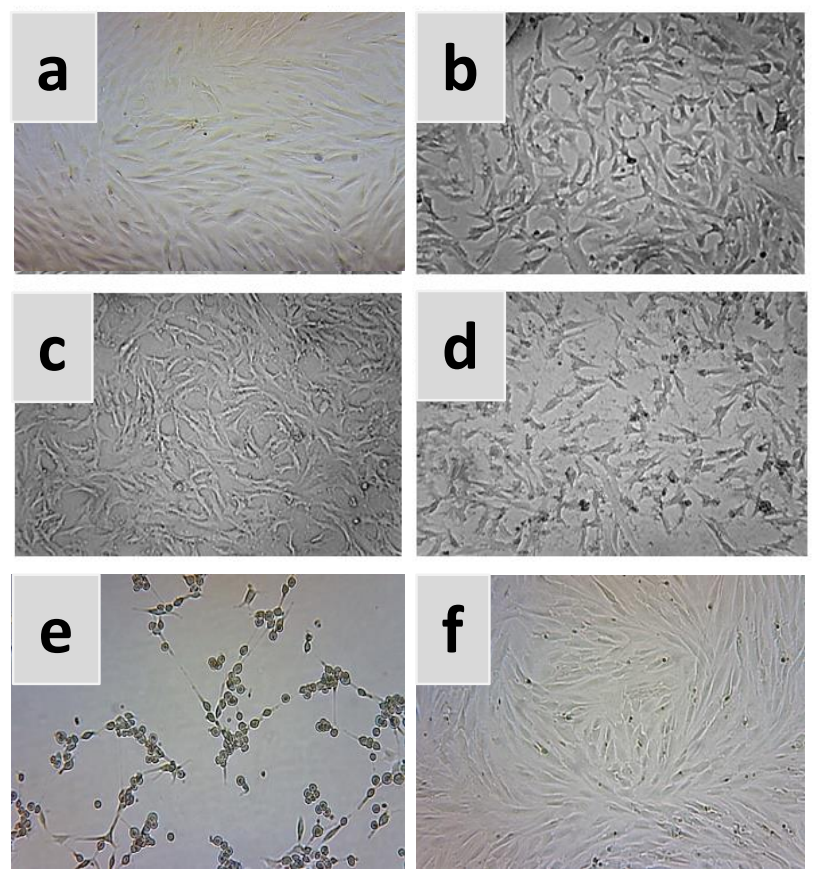

Figure 4 


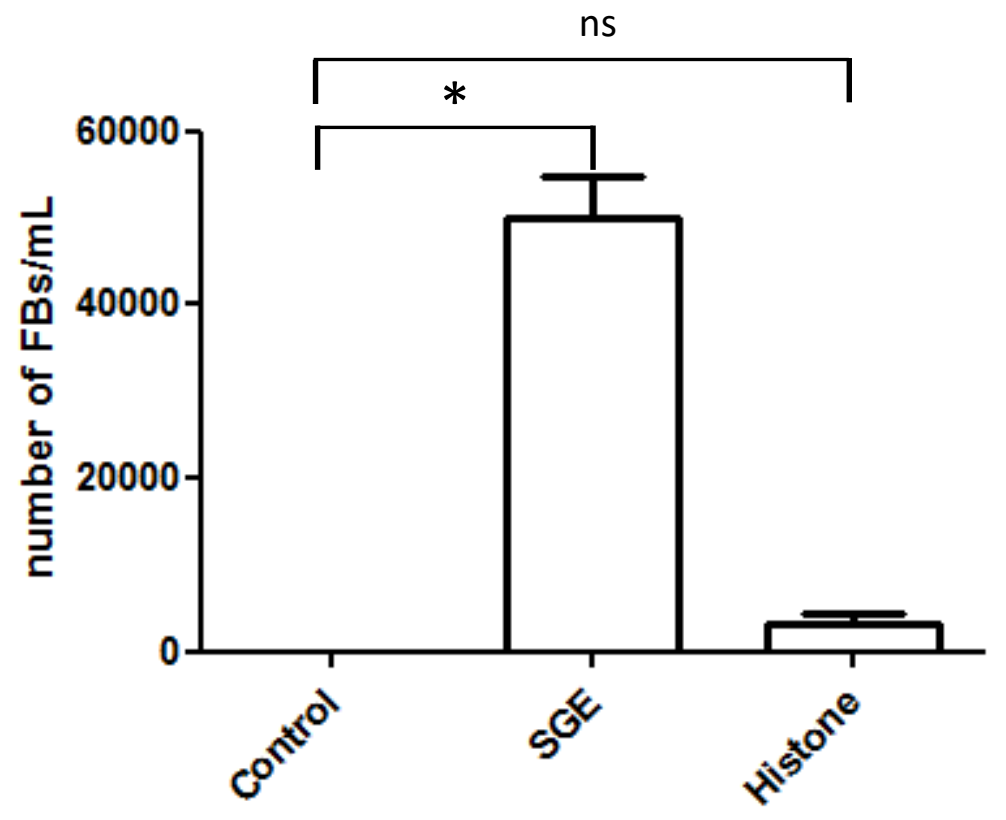

Figure 5 


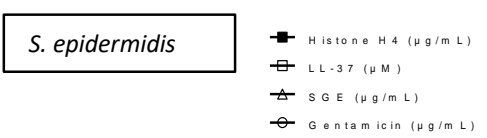

M. luteus

Gentamicin $(\mu g / m L$

A

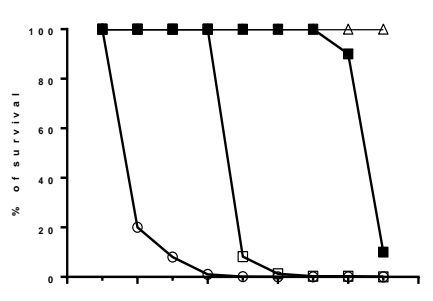

C

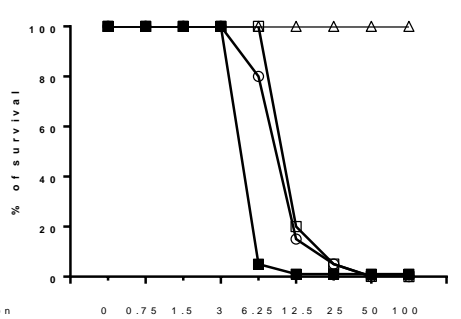

B

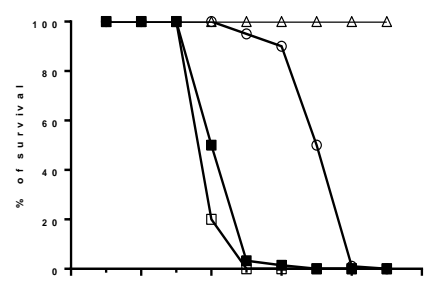

$\begin{array}{lllllllllll}\text { concentration } & 0 & 0.75 & 1.5 & 3 & 6.25 & 12.5 & 25 & 50 & 100\end{array}$

D

B. burgdorferi ss

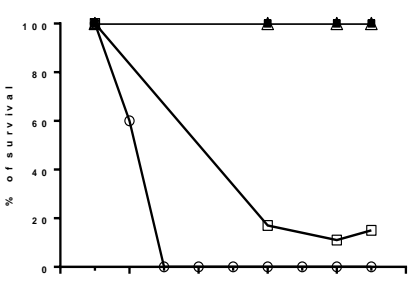

E

B. afzelii

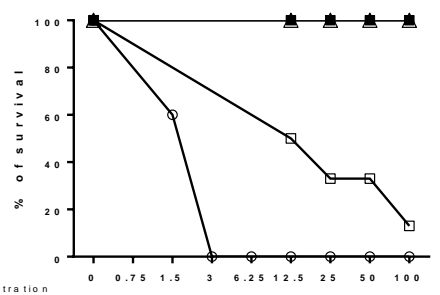

Figure 6 